\title{
MicroRNAs in Dopamine Agonist-Resistant Prolactinoma
}

\author{
Xueyan Wan Zisheng Yan Zhoubin Tan Zhi Cai Yiwei Qi Liang Lu \\ YuXu Juan Chen Ting Lei \\ Department of Neurosurgery, Tongji Hospital, Tongji Medical College, Huazhong University of Science and \\ Technology, Wuhan, China
}

\section{Keywords}

Dopamine agonist-resistant prolactinomas · Management · MicroRNAs · Pituitary tumors - Transforming growth factor- $\beta$ signaling

\section{Abstract}

Dopamine agonists (DAs) are preferred for the treatment of prolactinomas and are usually very effective. Nonetheless, $20-30 \%$ of bromocriptine- and approximately $10 \%$ of cabergoline-treated individuals exhibit resistance to DAs. In addition, the mechanism underlying this phenomenon remains elusive. In this study, we summarize the major findings regarding the role of microRNAs (miRNAs) in the pathogenesis of DA-resistant prolactinoma (DARP). Currently available evidence suggests that miRNAs are usually dysregulated in DARP and that, although controversial, the dysregulated miRNAs target the transforming growth factor (TGF)- $\beta$, dopamine 2 receptor (D2R), or estradiol (E2)/estrogen receptor (ER) signaling pathways to mediate the therapeutic effect of DAs. These findings provide new incentives for research on innovative strategies for predicting patients' responsiveness to dopamine therapies and for developing treatment approaches. Unfortunately, recent studies tended to focus exclusively on the differential miRNA expression profiles be- tween DARP and dopamine-sensitive prolactinoma, and no definitive consensus has been reached regarding the role of these miRNAs in the modulation mechanism. Therefore, current and future efforts should be directed toward the exploration of the mechanism underlying the dysregulation of miRNAs as well as of the target proteins that are affected by the dysregulated miRNAs. Furthermore, the modulation of the expression of dysregulated miRNAs, which target the D2R, TGF- $\beta$, or E2/ER signaling pathways, might be a promising alternative to treat patients with DARP and improve their prognosis.

(c) 2021 The Author(s)

Published by S. Karger AG, Basel

\section{Introduction}

Dopamine agonists (DAs) are preferred for and are generally highly effective for treating prolactinoma. However, $20-30 \%$ of bromocriptine (BRC)- and approximately $10 \%$ of cabergoline (CAB)-treated individuals are resistant to these agents. Moreover, the underlying mechanism remains to be determined. In this review, we summarize the major findings about the role of microRNAs (miRNAs) in the pathogenesis of DA-resistant prolactinoma (DARP).
(C) 2021 The Author(s)

Published by S. Karger AG, Basel

This is an Open Access article licensed under the Creative Common Attribution-NonCommercial-4.0 International License (CC BY-NC) (http://www.karger.com/Services/OpenAccessLicense), applicable to the online version of the article only. Usage and distribution for commercial purposes requires written permission.
Correspondence to:

Ting Lei, tlei@tjh.tjmu.edu.cn 


\section{DARP}

\section{Diagnosis of DARP}

Prolactinoma, which is the most prevalent neuroendocrine disease, represents approximately $40 \%$ of all pituitary lesions, which accounts for $10-15 \%$ of primary intracranial neoplasms [1]. Currently, DAs, including BRC and $\mathrm{CAB}$, are regarded as first-line drugs and are usually very effective in the treatment of prolactinomas [2]. However, some patients are unresponsive to treatment with DAs, even under maximally tolerated doses, which is considered as DA resistance [3]. Unfortunately, there is no consensus regarding the concept of DARP despite the emergence of new DA drugs and enhanced clinical therapeutic opportunities [1]. The treatment goals of prolactinomas, which are active adenomas, are to normalize the serum prolactin (PRL) levels and induce tumor shrinkage $[1,4,5]$. Initially, physicians simply focused on the hormonal response to the drugs and regarded the inability to reduce PRL levels sufficiently to achieve ovulation or the failure to induce $50 \%$ reduction in hyperprolactinemia as DARP $[4,6,7]$. In 2001, Di Sarno et al. [4] advocated that normalizing the serum PRL level and inducing tumor shrinkage should be the targets for prolactinoma treatment and defined this condition as the inability to normalize serum PRL levels and shrink tumors. However, regarding tumor reduction, several supplementary criteria have also been proposed in the literature, including changes in the maximum diameter, height, surface, or volume of tumors in CT or MRI scans during treatment with DAs, and favorable responses have been reported in terms of shrinkage percentage, ranging from 25 to $80 \%[4,8]$. As the risk of compression depends primarily upon tumor expansion to the optic chiasm, an appropriate parameter for tumor response appears to be a reduction in tumor height of $>30 \%$ or a decrease in tumor coronal surface of $>50 \%$ [9]. Therefore, Molitch's $[3,10]$ diagnosis of DARP uses the following criteria and are widely accepted and applied: (1) failure to achieve a normal PRL level at the maximum tolerated dose or (2) failure to reduce the tumor size by at least $50 \%$. According to this definition, he reported that hormonal resistance ranges from 11 for $\mathrm{CAB}$ to $24 \%$ for BRC, whereas insufficient reduction in tumor size was observed in 4 of CABand $36 \%$ of BRC-treated patients [5]. More recently, however, Maiter [8] reported that this simple definition is arbitrary. Considering the dose and the type of drug, as well as the period over which the drug is prescribed, he defined DARP as: (1) the failure to achieve normoprolactinemia under maximally tolerated doses of DA for at least 3-6 months and (2) the lack of $a \geq 30 \%$ reduction in tumor di- ameter. According to these criteria, the authors found that the incidence of resistant prolactinomas was approximately $20-30 \%$ for BRC, and that the hormonal resistance to $\mathrm{CAB}$ was $<10 \%$ for microprolactinomas and $15-20 \%$ for macroprolactinomas [10-12]. Therefore, the prevalence of DA resistance often varies widely among clinical studies because of the different definitions of DA resistance and the types of DA drugs used in specific studies.

\section{Management of DARP}

The management of DARP has been reviewed in detail previously $[8,13,14]$ and is not the focus of this review. In brief, a patient diagnosed with resistance to BRC should first switch to another DA, such as $\mathrm{CAB}$, and undergo treatment for 3-6 months with the maximal dose $(3.5 \mathrm{mg} /$ week $)[5,15]$. If the patient meets the requirements for a diagnosis of DARP discussed earlier and resistance to CAB has been confirmed, the physician should generally follow a sequence involving surgical debulking, radiotherapy, or administration of experimental medicines such as temozolomide $[5,8]$.

\section{Potential Mechanisms of DA Resistance}

The mechanism underlying DA resistance in prolactinoma remains elusive, although much effort has been dedicated to this subject. As shown in Figure 1, several potential mechanisms of DA resistance have been proposed, which are as follows: (1) decreased expression of dopamine 2 receptor (D2R) and small cellular downstream signaling molecules of dopamine receptors $[6,16-$ 21]; (2) alterations in other receptors that modulate the expression of the dopamine receptor, such as the nerve growth factor receptor [19], estrogen receptor (ER) [19, 22], and mTOR signaling [23]; (3) impairment of the transforming growth factor (TGF) $\beta$ signaling pathway [24-27]; and (4) dysregulation of miRNAs [27-30]. In this review, we focus on recent advances in the study of miRNAs, their potential involvement in the resistance to DA treatment, and future perspectives.

\section{miRNAs in DARP}

miRNAs in Prolactinoma

The first miRNA was discovered nearly 40 years ago in the nematode Caenorhabditis elegans with the identification of the developmental regulator lin 4. Currently, over 2,000 miRNAs have been identified in humans, and the dysregulated expression of miRNAs is believed to be associated with numerous pathological conditions, such as 


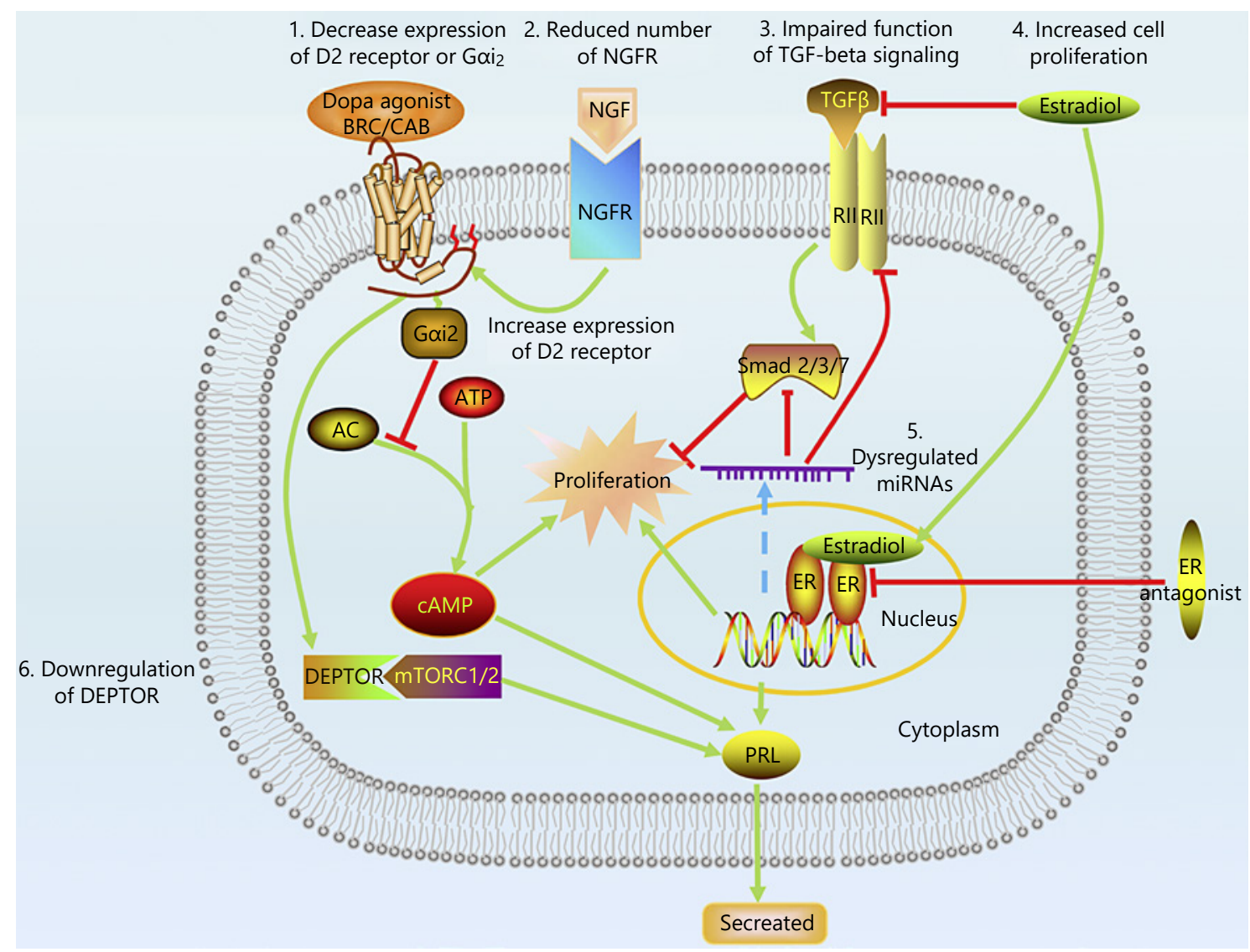

Fig. 1. Potential mechanisms involved in the DARP. DARP, dopamine agonist-resistant prolactinoma; D2R, dopamine 2 receptor; TGF, transforming growth factor; $\mathrm{BRC}$, bromocriptine; $\mathrm{CAB}$, cabergoline; miRNA, microRNA; ER, estrogen receptor; PRL, prolactin.

pituitary adenomas [31], cancer progression [32], and chemotherapy resistance [33]. Current evidence suggests that miRNAs play a vital role in pituitary development and pituitary hormone secretion [34-38]; moreover, dysregulated miRNA expression has been confirmed to be involved in pituitary disorders $[31,39,40]$.

The first investigation of miRNAs in patients with pituitary adenoma, which was conducted by Bottoni et al. [41], shed light on the role of miRNAs in pituitary adenoma and demonstrated that the expressions of miR-15a and miR-161 were downregulated in pituitary adenomas compared with those in normal pituitary tissue. Subsequent studies focused on differential miRNA expression between prolactinomas and the pituitary gland and their potential role in the tumorigenesis of prolactinomas. Table 1 summarizes the dysregulated miRNAs identified to date [42-47]. Collectively, these reports suggest that dysregulated miRNAs play a significant role in the development of prolactinomas via the mediation of the expression of target genes.
Recently, the focus of research in this field has shifted to the expression profile of miRNAs after pharmacological treatment: Wang et al. [48] examined 15 patients with prolactinoma and found that there were 80 upregulated miRNAs and 71 downregulated miRNAs in treated versus untreated patients. The expressions of miR-206, miR$516 \mathrm{~b}$, and miR-550 were confirmed to be significantly upregulated, whereas that of miR-671-5p was significantly downregulated in treated versus untreated prolactinomas. A subsequent bioinformatics analysis demonstrated that mitogen-activated protein kinase and survival (mTOR and TGF- $\beta$ ) signaling pathways, which are involved in the pathogenesis of DARP, were abundant among the significantly enriched pathways.

\section{miRNAs in DARP}

Current evidence suggests that some miRNAs and their target genes have been identified in DARP after the investigation of differential miRNA expression in pa- 


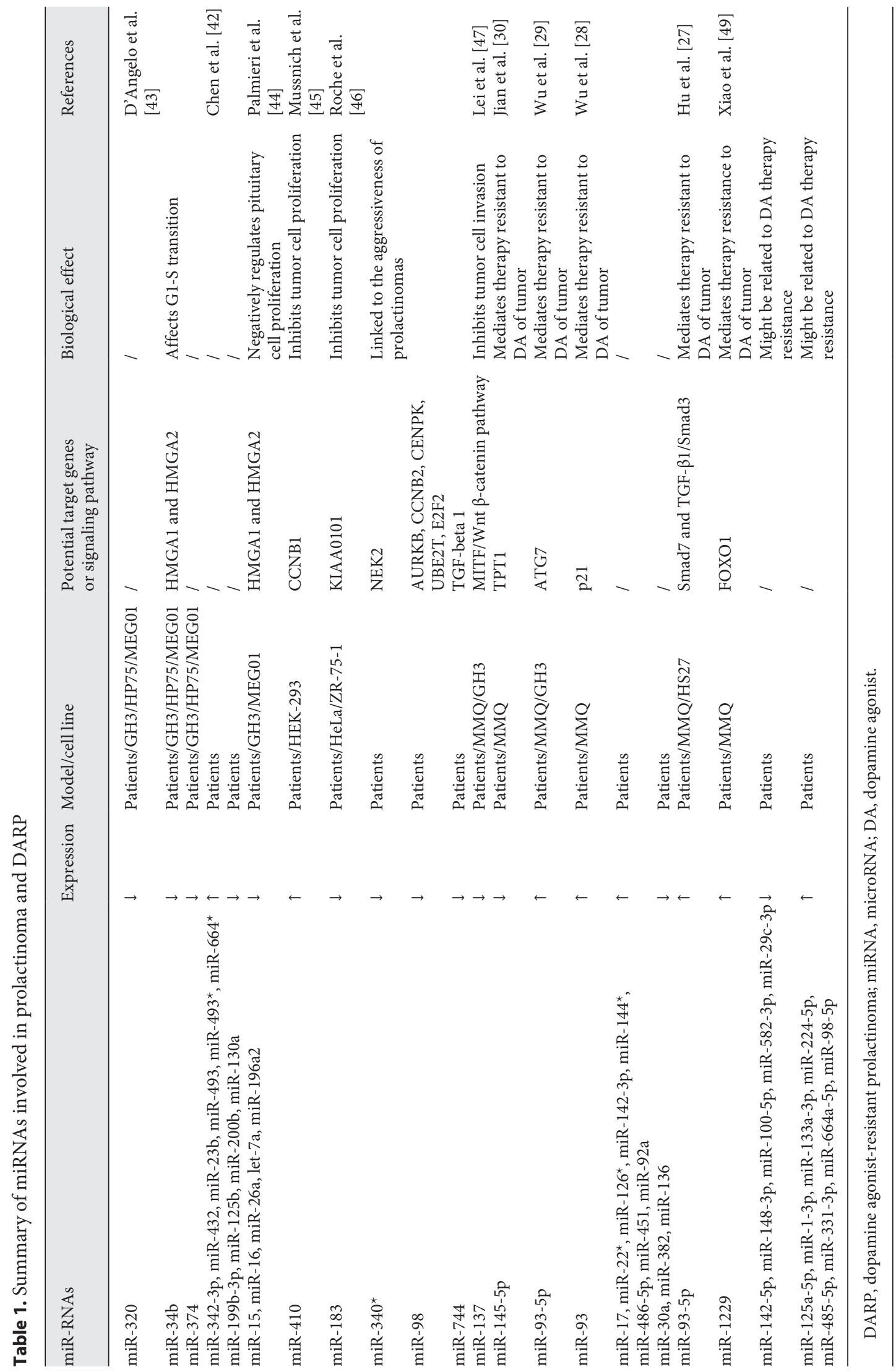




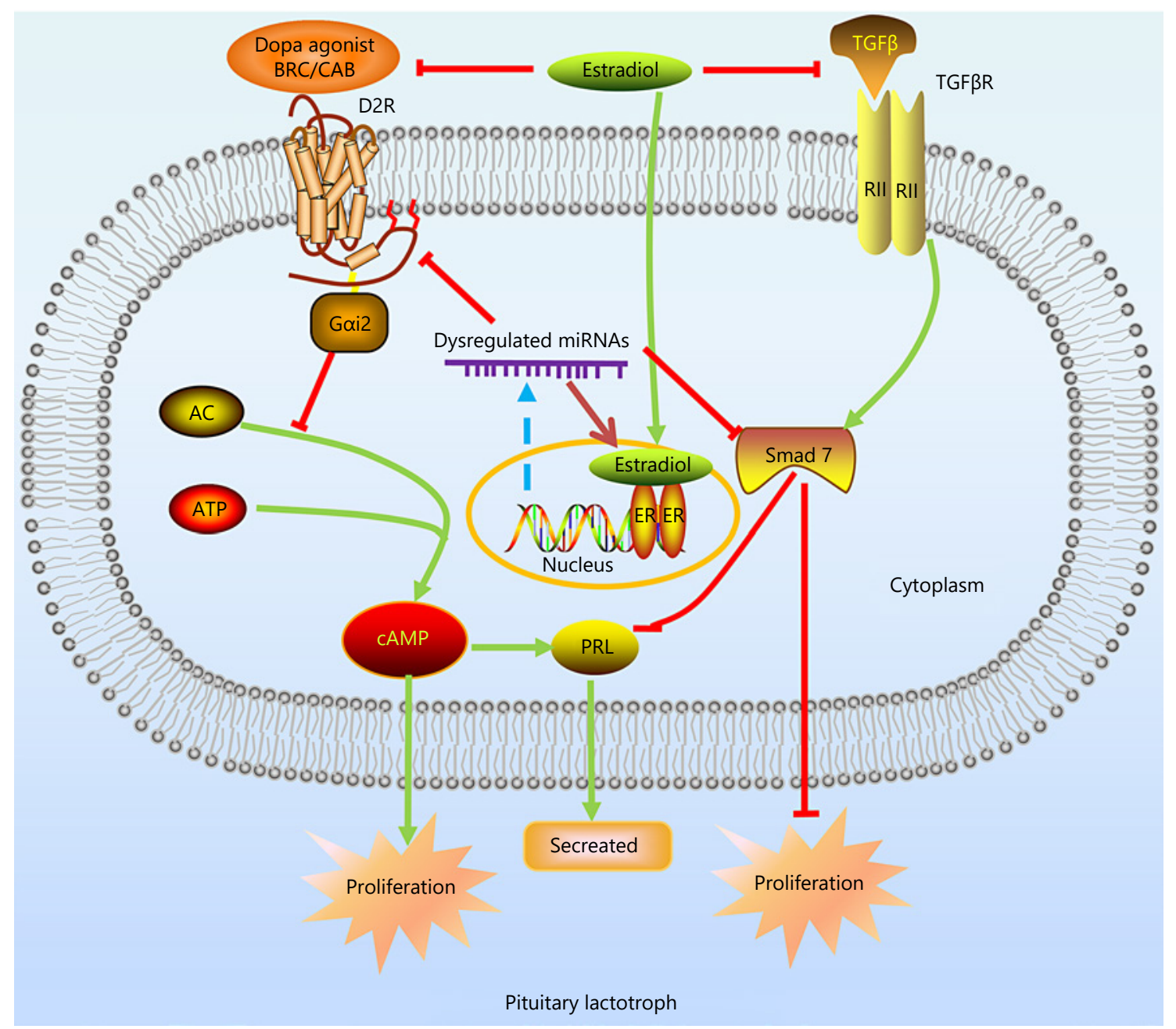

Fig. 2. Dysregulation of miRNA may be involved in DARP by impairing signaling of TGF receptors and D2R. DARP, dopamine agonist-resistant prolactinoma; miRNA, microRNA; TGF, transforming growth factor; D2R, dopamine 2 receptor; BRC, bromocriptine; $\mathrm{CAB}$, cabergoline; PRL, prolactin.

tients with DARP versus those with DA-sensitive prolactinoma. A study conducted by Wu's team [28] explored the expression of miRNAs in DARP and reported that 41 miRNAs were differentially expressed between the 2 groups. Among them, 9 miRNAs were confirmed to be upregulated and 3 were downregulated, and these results were validated using qRT-PCR. Further studies revealed that miR-93 could modulate the expression of p21, leading to an increased response of MMQ cells to dopamine treatment [28]. Wu et al. [29] also demonstrated that miR-93 was upregulated in DARP and mediated DA resistance through autophagy downregulation by targeting ATG7. Another study showed that miR-145-5p was an important regulator of BRC resistance by controlling TPT1 expression because the upregulation of miR-145-
$5 \mathrm{p}$ expression led to a reduction in the $\mathrm{IC}_{50}$ of the drug and an increase in TPT1 expression [30]. Moreover, Xiao et al. [49] reported that miR-1299 expression was upregulated in DARP and inhibited FOXO1 expression; the authors concluded that miR-1299 and FOXO1 are potential therapeutic targets for drug-resistant prolactinomas. These miRNAs are also summarized in Table 1.

\section{The Potential Role of miRNAs in DARP}

\section{miRNAs Might Mediate the TGF Signaling Pathway} in DARP

Accumulating evidence supports the contention that the TGF- $\beta 1$ signaling pathway is involved in the patho- 
genesis of DARP [24-27]. As a multifunctional cytokine, TGF- $\beta 1$ is secreted to the extracellular matrix by pituitary lactotrophs, where it inhibits the proliferation of and PRL secretion by lactotroph cells, mediated largely via TGF- $\beta$ type II receptors (TGF- $\beta$ RII), in a similar manner to that described for dopamine. Recently, a series of 12 patients who underwent surgery because of resistance to BRC exhibited a significant reduction of TGF- $\beta 1$ and the downstream intracellular effectors Smad2 and Smad3 compared with normal human anterior pituitaries [24]. Therefore, it is crucial to explore the potential mechanism of impairment of TGF- $\beta$ signaling pathways in DARP $[24,25]$. Recently, dysregulated miRNAs have drawn much attention because miRNAs can regulate the expression of their target genes. Posttranscriptional regulation of the TGF- $\beta$ signaling pathway by miRNAs, including miR-93 [27], miR-142-3p [50], and miR-30a [51], may have effects in DARP (Fig. 2). In 2014, Wu et al. [28] investigated the miRNA expression profile of patients with resistance to BRC compared with those sensitive to BRC. Forty-one miRNAs were differentially expressed between the 2 groups, according to Solexa sequencing. Using stem-loop qRT-PCR to verify the differential expression of these miRNAs, the authors showed that the expressions of miR-93, miR-17, miR-22*, miR-126*, miR-1423p, miR-144*, miR-486-5p, miR-451, and miR-92a were upregulated, whereas those of miR-30a, miR-382, and miR-136 were downregulated in BRC-resistant prolactinomas. Finally, the authors selected miR-93 as a candidate miRNA for biological function analysis. A further study performed using MMQ cells, which are a cell type isolated from the 7315a rat prolactinoma that are responsive to dopamine [52], indicated that miR-93 (which targets the $3^{\prime}$-UTR of p21) silencing resulted in increased sensitivity of the cells to DA treatment by increasing p 21 expression in the cells [28]. Interestingly, p21, which is mediated by miR-93, played a significant role in G1 arrest and was a potent cyclin-dependent kinase inhibitor that was required for TGF- $\beta$-mediated cell cycle arrest in melanoma [53]. More recently, $\mathrm{Hu}$ et al. [27] demonstrated that miR-93-5p targeted Smad7 to regulate the TGF- $\beta 1 /$ Smad3 pathway and mediated fibrosis in drug-resistant prolactinoma. Using high-throughput sequencing for the analysis of miRNAs, they found that miR-93-5p expression was significantly upregulated in prolactinoma samples with a high degree of fibrosis compared with that in samples without fibrosis. Furthermore, they demonstrated that miR-93-5p expression was negatively correlated with Smad7 expression and positively correlated with TGF- $\beta 1$ expression in clinical prolactinoma samples. Lu- ciferase reporter assays supported the contention that miR-93-5p could downregulate the Smad7 gene and activate TGF- $\beta 1 / \mathrm{Smad} 3$-signaling-mediated fibrosis in a feed-forward loop. Hence, miR-93-5p could enhance the drug resistance of prolactinoma cells by regulating TGF- $\beta 1 /$ Smad3-dependent fibrosis [27]. In addition to miR-93, miR-142-3p expression was also confirmed to be upregulated in patients with DARP [28] and was found to mediate TGF- $\beta$ receptor expression in non-small cell lung cancer [50]. Whether miRNA-142-3p is involved in resistance to DA therapy and the mechanism underlying this phenomenon require further investigation.

\section{miRNAs Might Mediate D2R Transcription in DARP}

The potential structure of DA treatment aiming at decreasing serum PRL levels and shrinking tumor sizes was discussed by Liu et al. [54]. They hypothesized that treatment with BRC and CAB induces pituitary adenoma cell death possibly through 3 mechanisms: apoptosis, autophagic cell death, and paraptosis [54]. This report supports the hypothesis that the therapeutic effect of DA is mediated by D2R or dopamine transporters present on the surface of lactotroph cells. Therefore, most researchers have focused on the structure, ligand affinity, isoforms, and density of D2R, as well as the intracellular transduction of the $\mathrm{D} 2 \mathrm{R}$ signaling pathway in resistant prolactinomas [6, 17]. Current evidence suggests that $D 2 R$ expression is downregulated in DARP $[17,19,20]$. This decreased D2R expression not only directly decreases the therapeutic effect of DA but also results in the decrease of both TGF- $\beta 1$ secretion and TGF- $\beta$ RII expression in lactotroph cells [55], which in turn lessens the sensitivity of the response to DA.

D2R exhibits 2 alternatively spliced isoforms: the long (D2L) and short (D2S) forms. D2S is characterized by the absence of 29 amino acid residues within the third intracellular loop [56] compared with D2L. Both isoforms have been shown to exhibit comparable affinity to the ligand and might activate distinct intracellular signal transduction pathways to maintain lactotroph homeostasis in physiological conditions $[57,58]$. In fact, the physiological function of the 2 isoforms remains elusive. D2S might inhibit PRL synthesis and lactotroph cell proliferation, whereas D2L might facilitate PRL secretion [59]. Increasing evidence indicates that the D2S/D2L ratio might play a part in the responsiveness of prolactinoma to DA medication [20, 21, 60]. Caccavelli et al. [17] found that the $\mathrm{D} 2 \mathrm{~S} / \mathrm{D} 2 \mathrm{~L}$ ratio was lower in resistant patients than in responsive patients. Wu et al. [20] also demonstrated that lower D2S expression and higher D2L expression were 
related to the resistance of prolactinomas to DA medication. A subsequent study by them showed that forced D2S expression via adenovirus-mediated D2S transfer could sensitize GH3 cells to BRC therapy in vitro and in vivo. They speculated that adenovirus-mediated D2S transfer combined with BRC treatment may serve as a novel approach for the treatment of DARP [60]. However, other research studies demonstrated that the D2L expression level is associated with responsiveness to DA treatment in prolactinomas. Passos et al. [19] reported that 2 patients with drug-resistant prolactinomas exhibited high D2R expression. They speculated that there could be a predominance of the D2L over the D2S receptor subtype. Shimazu et al. [21] reported that the reduction of the D2L mRNA level is correlated with resistance to DAs in prolactinoma.

D2R polymorphism has also been evaluated, and the NcoI-T allele was found to be significantly associated with biological and radiological resistance to DAs [61]. However, another study found no correlation between D2R polymorphism and $\mathrm{CAB}$ responsiveness in patients with prolactinomas [62].

The modulation and mechanisms underlying decreased D2R expression have also attracted attention. Many miRNAs, including miR-9 [37], miR-326 [63], and miR-200a [64], target D2R expression. In 2017, Gangisetty et al. [37] reported that upregulated expression of miR-9 produced by the pituitary of Fischer 344 rats under fetal alcohol exposure could repress D2S expression by targeting its $3^{\prime}$-UTR, resulting in an increase in PRL production and secretion. However, the role of dysregulated miRNAs after exposure to DAs in mediating D2R expression in DARP should be examined further.

\section{miRNAs Might Mediate the E2/ER Signaling Pathway} in DARP

Estradiol (E2) has been acknowledged to play a vital role in the tumorigenesis of pituitary adenoma in rats $[65$, 66], and it appears to increase the risk factors for prolactinomas in humans [67-69]. The interaction of E2 with the TGF- $\beta$ system and D2R has been also described [69]. When exposed to E2, TGF- $\beta 1$ and TGF- $\beta$ RII expression is downregulated in lactotroph cells [70, 71]. Moreover, $\mathrm{E} 2$ reduces both the levels of dopamine and $\mathrm{D} 2 \mathrm{R}$ activity [72-74] and increases the D2L/D2S ratio [74-76] in lactotroph cells. Based on the evidence described above, it is reasonable to presume that the E2 signaling pathway is involved in the responsiveness of prolactinomas to DAs. The biological effects of estrogen are mainly mediated by $\mathrm{ER} \alpha$; therefore, the association between ER $\alpha$ expression and responsiveness to DA therapy has been studied intensively. Wu et al. [20] found that the median ERa mRNA expression in resistant patients was 1.5-fold higher than that in responsive patients. Passos et al. [19] and Cristina et al. [77] obtained similar results, demonstrating that ER $\alpha$ expression was higher in resistant patients, although ERa expression was not significantly different between the responsive and resistant groups. However, Delgrange et al. [78] reported that patients who were resistant to medical treatment were mainly male; PRL tumors in men are characterized by low ERa expression, which was related to resistance to treatment and overall poor prognosis. Therefore, no consensus has been reached on this topic, and further investigation regarding gender disparities in the response to DA treatment is necessary. Finally, a better understanding of the mechanisms underlying such phenomena will enable the development of optimal therapeutics.

The correlation between miRNAs and estrogen action has also been reviewed $[79,80]$. Many of the dysregulated miRNAs identified in resistant prolactinomas (Table 1) are reported to potentially modulate E2 and ERa expression in different conditions. Under hypoxia, increased miR-98 expression was suspected to contribute to a reduction in E2 production through the downregulation of CYP19A1 mRNA and protein expressions in H295R cells [81]. miR-224 was found to promote E2 secretion from granulosa cells, partially by increasing CYP19A1 mRNA levels [82, 83]. Moreover, Hossain et al. [84] demonstrated that miR-17-5p repressed ER-mediated signal transduction pathways by targeting AIBI in breast cancer cells, and miR-142-3p was proven to inhibit ER expression in ER-positive breast cancer [85]. Spizzo et al. [86] found that miR-145 could downregulate ERa protein expression through direct interaction with 2 complementary sites within its coding sequence in breast cancer cells. However, to date, there is no direct evidence that dysregulated miRNAs modulate E2 and ERa expression in DARP; thus, further investigation is required to clarify whether the dysregulated miRNA expression in DARP impairs the responsiveness to DA therapy via the E2/ER signaling pathway.

\section{Conclusion}

To date, the management of DARP remains challenging in clinical scenarios. It is reasonable to explore potential mechanisms and alternative medical treatments to improve the prognosis of patients with DARP. As one of 
its characteristics, the dysregulation of miRNA expression, although debatable, might contribute to the regulation of D2R, TGF- $\beta$, and estrogen signaling pathways. These findings provide new incentives for research on innovative strategies for predicting patients' responsiveness to dopamine therapies and developing treatment approaches. However, recent studies tended to focus solely on the differential expression profiles of miRNAs between DARP and dopamine-sensitive prolactinomas, and no definitive consensus has been reached regarding the role of these miRNAs or the mechanism of modulation. Therefore, research efforts should be directed to explore the mechanism underlying the dysregulation of miRNAs as well as their target proteins. The identification and monitoring of the expression profiles of miRNAs might be useful to predict pharmacological responses and assist in the classification of prolactinomas (DA sensitive and resistant) before treatment initiation. Furthermore, modulation of the expression of dysregulated miRNAs, which target the D2R, TGF- $\beta$, or estrogen signaling pathways, might be a promising alternative for the management of patients and for improving the prognosis of DARP.

\section{Acknowledgment}

The authors would like to thank Dr. Rajluxmee Beejadhursing for linguistic assistance and critical reading during the preparation of this manuscript.

\section{Conflict of Interest Statement}

There are no conflicts of interest.

\section{Funding Sources}

This research was funded by the Scientific Research Starting Foundation for Returned Overseas Chinese Scholars from Tongji Hospital, Tongji Medical College, Huazhong University of Science and Technology (2020HGRY009), and Nature Science Foundation of Hubei Province (2019CFB316).

\section{Author Contributions}

Conceptualization and methodology: X.W. and T.L.; investigation and original draft preparation: X.W., Z.Y., Z.T., Z.C., Y.Q., L.L., Y.X., J.C., and T.L.; review and editing: X.W., Z.T., Y.X., J.C., and T.L.; supervision: X.W., Y.X., J.C., and T.L.

\section{References}

1 Oh MC, Aghi MK. Dopamine agonist-resistant prolactinomas. J Neurosurg. 2011 May; 114(5):1369-79.

2 Vroonen L, Daly AF, Beckers A. Epidemiology and management challenges in prolactinomas. Neuroendocrinology. 2019;109(1): 20-7.

3 Molitch ME. Pharmacologic resistance in prolactinoma patients. Pituitary. 2005;8(1): 43-52.

4 Di Sarno A, Landi ML, Cappabianca P, Di Salle F, Rossi FW, Pivonello R, et al. Resistance to cabergoline as compared with bromocriptine in hyperprolactinemia: prevalence, clinical definition, and therapeutic strategy. J Clin Endocrinol Metab. 2001 Nov;86(11):5256-61.

5 Molitch ME. Dopamine resistance of prolactinomas. Pituitary. 2003;6(1):19-27.

6 Pellegrini I, Rasolonjanahary R, Gunz G, Bertrand P, Delivet S, Jedynak CP, et al. Resistance to bromocriptine in prolactinomas. J Clin Endocrinol Metab. 1989 Sep;69(3):500-9.

7 Delgrange E, Maiter D, Donckier J. Effects of the dopamine agonist cabergoline in patients with prolactinoma intolerant or resistant to bromocriptine. Eur J Endocrinol. 1996 Apr; 134(4):454-6.

8 Maiter D. Management of dopamine agonistresistant prolactinoma. Neuroendocrinology. 2019;109(1):42-50.
9 Delgrange E, Duprez T, Maiter D. Influence of parasellar extension of macroprolactinomas defined by magnetic resonance imaging on their responsiveness to dopamine agonist therapy. Clin Endocrinol. 2006 Apr;64(4): 456-62.

10 Molitch ME. Management of medically refractory prolactinoma. J Neurooncol. 2014 May;117(3):421-8.

11 Gillam MP, Molitch ME, Lombardi G, Colao A. Advances in the treatment of prolactinomas. Endocr Rev. 2006 Aug;27(5):485-534.

12 Vasilev V, Daly AF, Vroonen L, Zacharieva S, Beckers A. Resistant prolactinomas. J Endocrinol Invest. 2011 Apr;34(4):312-6.

13 Sahakian N, Castinetti F, Dufour H, Graillon $\mathrm{T}$, Romanet $\mathrm{P}$, Barlier A, et al. Clinical management of difficult to treat macroprolactinomas. Expert Rev Endocrinol Metab. 2019 May;14(3):179-92.

14 Souteiro P, Karavitaki N. Dopamine agonist resistant prolactinomas: any alternative medical treatment. Pituitary. 2020 Feb;23(1):2737.

15 Huang HY, Zhai W, Tang H, Hui GZ, Wu ZB. Cabergoline for the treatment of bromocriptine-resistant invasive giant prolactinomas. Endocrine. 2018;62(2):464-9.

16 Wood DF, Johnston JM, Johnston DG. Dopamine, the dopamine $\mathrm{D} 2$ receptor and pitu- itary tumours. Clin Endocrinol. 1991 Dec; 35(6):455-66.

17 Caccavelli L, Feron F, Morange I, Rouer E, Benarous R, Dewailly D, et al. Decreased expression of the two D2 dopamine receptor isoforms in bromocriptine-resistant prolactinomas. Neuroendocrinology. 1994 Sep;60(3): 314-22.

18 Caccavelli L, Morange-Ramos I, Kordon C, Jaquet P, Enjalbert A. Alteration of G alpha subunits mRNA levels in bromocriptine resistant prolactinomas. J Neuroendocrinol. 1996 Oct;8(10):737-46.

19 Passos VQ, Fortes MA, Giannella-Neto D, Bronstein MD. Genes differentially expressed in prolactinomas responsive and resistant to dopamine agonists. Neuroendocrinology. 2009;89(2):163-70.

$20 \mathrm{Wu} Z \mathrm{ZB}$, Zheng WM, Su ZP, Chen Y, Wu JS, Wang $C D$, et al. Expression of D2RmRNA isoforms and ERmRNA isoforms in prolactinomas: correlation with the response to bromocriptine and with tumor biological behavior. J Neurooncol. 2010 Aug;99(1):25-32.

21 Shimazu S, Shimatsu A, Yamada S, Inoshita $\mathrm{N}$, Nagamura $\mathrm{Y}$, Usui T, et al. Resistance to dopamine agonists in prolactinoma is correlated with reduction of dopamine $\mathrm{D} 2$ receptor long isoform mRNA levels. Eur J Endocrinol. 2012 Mar;166(3):383-90. 
22 Mahboobifard F, Bidari-Zerehpoosh F, Davoudi Z, Panahi M, Dargahi L, Pourgholami MH, et al. Expression patterns of ERa66 and its novel variant isoform ERa36 in lactotroph pituitary adenomas and associations with clinicopathological characteristics. Pituitary. 2020 Jun;23(3):232-45.

23 Yao H, Tang H, Zhang Y, Zhang QF, Liu XY, Liu YT, et al. DEPTOR inhibits cell proliferation and confers sensitivity to dopamine agonist in pituitary adenoma. Cancer Lett. 2019 Sep 10;459:135-44.

24 Li Z, Liu Q, Li C, Zong X, Bai J, Wu Y, et al. The role of TGF- $\beta /$ Smad signaling in dopamine agonist-resistant prolactinomas. Mol Cell Endocrinol. 2015 Feb 15;402:64-71.

25 Recouvreux MV, Camilletti MA, Rifkin DB, Díaz-Torga G. The pituitary TGF $\beta 1$ system as a novel target for the treatment of resistant prolactinomas. J Endocrinol. 2016 Mar; 228(3):R73-83.

$26 \mathrm{Hu}$ B, Mao Z, Jiang X, He D, Wang Z, Wang $X$, et al. Role of TGF- $\beta 1 / \mathrm{Smad} 3$-mediated fibrosis in drug resistance mechanism of prolactinoma. Brain Res. 2018 Nov 1;1698:20412.

27 Hu B, Mao Z, Du Q, Jiang X, Wang Z, Xiao Z, et al. miR-93-5p targets $S \operatorname{mad} 7$ to regulate the transforming growth factor- $\beta 1 / \mathrm{Smad} 3$ pathway and mediate fibrosis in drug-resistant prolactinoma. Brain Res Bull. 2019 Jul;149: $21-31$.

$28 \mathrm{Wu}$ ZB, Li WQ, Lin SJ, Wang CD, Cai L, Lu $\mathrm{JL}$, et al. MicroRNA expression profile of bromocriptine-resistant prolactinomas. Mol Cell Endocrinol. 2014 Sep;395(1-2):10-8.

$29 \mathrm{Wu}$ Z, Cai L, Lu J, Wang C, Guan J, Chen X, et al. MicroRNA-93 mediates cabergoline-resistance by targeting ATG7 in prolactinoma. The J Endocrinol. 2018 Sep 1. Epub ahead of print.

30 Jian M, Du Q, Zhu D, Mao Z, Wang X, Feng $Y$, et al. Tumor suppressor miR-145-5p sensitizes prolactinoma to bromocriptine by downregulating TPT1. J Endocrinol Invest. 2019 Jun;42(6):639-52.

31 Wierinckx A, Roche M, Legras-Lachuer C, Trouillas J, Raverot G, Lachuer J. MicroRNAs in pituitary tumors. Mol Cell Endocrinol. 2017;456:51-61.

32 Harrandah AM, Mora RA, Chan EKL. Emerging microRNAs in cancer diagnosis, progression, and immune surveillance. Cancer Lett. 2018 Dec 1;438:126-32.

33 Si W, Shen J, Zheng H, Fan W. The role and mechanisms of action of microRNAs in cancer drug resistance. Clin Epigenetics. 2019 Feb 11;11(1):25.

34 Ye RS, Xi QY, Qi Q, Cheng X, Chen T, Li H, et al. Differentially expressed miRNAs after GnRH treatment and their potential roles in $\mathrm{FSH}$ regulation in porcine anterior pituitary cell. PLoS One. 2013;8(2):e57156.

35 Zhang N, Lin JK, Chen J, Liu XF, Liu JL, Luo HS, et al. MicroRNA 375 mediates the signaling pathway of corticotropin-releasing factor (CRF) regulating pro-opiomelanocortin
(POMC) expression by targeting mitogen-activated protein kinase 8. J Biol Chem. 2013 Apr 12;288(15):10361-73.

36 Lannes J, L'Hôte D, Garrel G, Laverrière JN, Cohen-Tannoudji J, Quérat B. Rapid communication: a microRNA-132/212 pathway mediates $\mathrm{GnRH}$ activation of FSH expression. Mol Endocrinol. 2015 Mar;29(3):364-72.

37 Gangisetty O, Jabbar S, Wynne O, Sarkar DK. MicroRNA-9 regulates fetal alcohol-induced changes in D2 receptor to promote prolactin production. J Endocrinol. 2017 Oct;235(1): $1-14$.

38 Yu ZW, Gao W, Feng XY, Zhang JY, Guo HX, Wang CJ, et al. Roles of differential expression of miR-543-5p in GH regulation in rat anterior pituitary cells and GH3 cells. PLoS One. 2019;14(9):e0222340.

39 Gentilin E, Degli Uberti E, Zatelli MC. Strategies to use microRNAs as therapeutic targets. Best Pract Res Clin Endocrinol Metab. 2016 Oct;30(5):629-39.

40 Feng Y, Mao ZG, Wang X, Du Q, Jian M, Zhu $\mathrm{D}$, et al. MicroRNAs and target genes in pituitary adenomas. Horm Metab Res. 2018 Mar; 50(3):179-92.

41 Bottoni A, Piccin D, Tagliati F, Luchin A, Zatelli MC, Degli Uberti EC. miR-15a and miR16-1 down-regulation in pituitary adenomas. J Cell Physiol. 2005;204(1):280-5.

42 Chen YX, Li Q, Wang CD, Su ZP, Li WQ, Chen XB, et al. [Differential expression analysis of prolactinoma-related microRNAs]. Zhonghua Yi Xue Za Zhi. 2012 Feb 7;92(5): 320-3.

43 D'Angelo D, Palmieri D, Mussnich P, Roche M, Wierinckx A, Raverot G, et al. Altered microRNA expression profile in human pituitary GH adenomas: down-regulation of miRNA targeting HMGA1, HMGA2, and E2F1. J Clin Endocrinol Metab. 2012;97(7):E112838.

44 Palmieri D, D'Angelo D, Valentino T, De Martino I, Ferraro A, Wierinckx A, et al. Downregulation of HMGA-targeting microRNAs has a critical role in human pituitary tumorigenesis. Oncogene. 2012 Aug 23; 31(34):3857-65.

45 Mussnich P, Raverot G, Jaffrain-Rea ML, Fraggetta F, Wierinckx A, Trouillas J, et al. Downregulation of miR-410 targeting the cyclin B1 gene plays a role in pituitary gonadotroph tumors. Cell Cycle. 2015;14(16):25907.

46 Roche M, Wierinckx A, Croze S, Rey C, Legras-Lachuer C, Morel AP, et al. Deregulation of miR-183 and KIAA0101 in aggressive and malignant pituitary tumors. Front Med. 2015; 2:54.

47 Lei C, Jing G, Jichao W, Xiaohui L, Fang Q, Hua G, et al. MiR-137's tumor suppression on prolactinomas by targeting MITF and modulating Wnt signaling pathway. J Clin Endocrinol Metab. 2019 Dec 1;104(12):6391-402.

48 Wang C, Su Z, Sanai N, Xue X, Lu L, Chen Y, et al. microRNA expression profile and differentially-expressed genes in prolactinomas fol- lowing bromocriptine treatment. Oncol Rep. 2012 May;27(5):1312-20.

49 Xiao Z, Wang Z, Hu B, Mao Z, Zhu D, Feng $\mathrm{Y}$, et al. MiR-1299 promotes the synthesis and secretion of prolactin by inhibiting FOXO1 expression in drug-resistant prolactinomas. Biochem Biophys Res Commun. 2019 Nov 26;520(1):79-85.

50 Lei Z, Xu G, Wang L, Yang H, Liu X, Zhao J, et al. MiR-142-3p represses TGF- $\beta$-induced growth inhibition through repression of TGF $\beta R 1$ in non-small cell lung cancer. FASEB J. 2014;28(6):2696-704.

51 Jiang LH, Zhang HD, Tang JH. MiR-30a: a novel biomarker and potential therapeutic target for cancer. J Oncol. 2018;2018:5167829.

52 Judd AM, Login IS, Kovacs K, Ross PC, Spangelo BL, Jarvis WD, et al. Characterization of the MMQ cell, a prolactin-secreting clonal cell line that is responsive to dopamine. Endocrinology. 1988 Nov;123(5):2341-50.

53 Humbert L, Ghozlan M, Canaff L, Tian J, Lebrun JJ. The leukemia inhibitory factor (LIF) and p 21 mediate the TGFbeta tumor suppressive effects in human cutaneous melanoma. BMC cancer. 2015 Mar 29;15:200.

54 Liu X, Tang C, Wen G, Zhong C, Yang J, Zhu $\mathrm{J}$, et al. The mechanism and pathways of dopamine and dopamine agonists in prolactinomas. Front Endocrinol. 2018;9:768.

55 Recouvreux MV, Guida MC, Rifkin DB, Becu-Villalobos D, Díaz-Torga G. Active and total transforming growth factor- $\beta 1$ are differentially regulated by dopamine and estradiol in the pituitary. Endocrinology. $2011 \mathrm{Jul}$; 152(7):2722-30.

56 Giros B, Sokoloff P, Martres MP, Riou JF, Emorine LJ, Schwartz JC. Alternative splicing directs the expression of two D2 dopamine receptor isoforms. Nature. 1989 Dec 21-28. 342(6252):923-6

57 Radl D, De Mei C, Chen E, Lee H, Borrelli E. Each individual isoform of the dopamine D2 receptor protects from lactotroph hyperplasia. Mol Endocrinol. 2013 Jun;27(6):953-65.

58 Roof AK, Jirawatnotai S, Trudeau T, Kuzyk C, Wierman ME, Kiyokawa $\mathrm{H}$, et al. The balance of PI3K and ERK signaling is dysregulated in prolactinoma and modulated by dopamine. Endocrinology. 2018 Jun 1;159(6):2421-34.

59 Iaccarino C, Samad TA, Mathis C, Kercret H, Picetti R, Borrelli E. Control of lactotrop proliferation by dopamine: essential role of signaling through D2 receptors and ERKs. Proc Natl Acad Sci USA. 2002 Oct 29;99(22): 14530-5.

60 Li Q, Su Z, Liu J, Cai L, Lu J, Lin S, et al. Dopamine receptor D2S gene transfer improves the sensitivity of GH3 rat pituitary adenoma cells to bromocriptine. Mol Cell Endocrinol. 2014 Jan 25;382(1):377-84.

61 Filopanti M, Barbieri AM, Angioni AR, Colao A, Gasco V, Grottoli S, et al. Dopamine D2 receptor gene polymorphisms and response to cabergoline therapy in patients with prolactin-secreting pituitary adenomas. Pharmacogenomics J. 2008 Oct;8(5):357-63. 
62 Bueno C, Trarbach EB, Bronstein MD, Glezer A. Cabergoline and prolactinomas: lack of association between DRD2 polymorphisms and response to treatment. Pituitary. 2017 Jun; 20(3):295-300.

63 Shi S, Leites C, He D, Schwartz D, Moy W, Shi J, et al. MicroRNA-9 and microRNA-326 regulate human dopamine D2 receptor expression, and the microRNA-mediated expression regulation is altered by a genetic variant. J Biol Chem. 2014 May 9;289(19):13434-44.

64 Wu DM, Wang S, Wen X, Han XR, Wang YJ, Shen $M$, et al. Inhibition of microRNA-200a upregulates the expression of striatal dopamine receptor D2 to repress apoptosis of striatum via the cAMP/PKA signaling pathway in rats with Parkinson's disease. Cell Physiol Biochem. 2018;51(4):1600-15.

65 De Nicola AF, von Lawzewitsch I, Kaplan SE, Libertun C. Biochemical and ultrastructural studies on estrogen-induced pituitary tumors in F344 rats. J Natl Cancer Inst. 1978 Sep; 61(3):753-63.

66 Wiklund J, Wertz N, Gorski J. A comparison of estrogen effects on uterine and pituitary growth and prolactin synthesis in F344 and Holtzman rats. Endocrinology. 1981 Nov; 109(5):1700-7.

67 Shy KK, McTiernan AM, Daling JR, Weiss NS. Oral contraceptive use and the occurrence of pituitary prolactinoma. JAMA. 1983 Apr 22-29;249(16):2204-7.

68 Gooren LJ, Assies J, Asscheman H, de Slegte $\mathrm{R}$, van Kessel H. Estrogen-induced prolactinoma in a man. J Clin Endocrinol Metab. 1988 Feb;66(2):444-6.

69 Sarkar DK. Genesis of prolactinomas: studies using estrogen-treated animals. Front Horm Res. 2006;35:32-49.

70 Pastorcic M, De A, Boyadjieva N, Vale W, Sarkar DK. Reduction in the expression and action of transforming growth factor beta 1 on lactotropes during estrogen-induced tumorigenesis in the anterior pituitary. Cancer Res. 1995 Nov 1;55(21):4892-8.
71 Pastorcic M, Sarkar DK. Downregulation of TGF-beta 1 gene expression in anterior pituitary cells treated with forskolin. Cytokine. 1997 Feb;9(2):106-11.

72 Raymond V, Beaulieu M, Labrie F, Boissier J. Potent antidopaminergic activity of estradiol at the pituitary level on prolactin release. Science. 1978 Jun 9;200(4346):1173-5.

73 Sarkar DK, Gottschall PE, Meites J. Damage to hypothalamic dopaminergic neurons is associated with development of prolactin-secreting pituitary tumors. Science. 1982 Nov 12;218(4573):684-6.

74 Oomizu S, Boyadjieva N, Sarkar DK. Ethanol and estradiol modulate alternative splicing of dopamine D2 receptor messenger RNA and abolish the inhibitory action of bromocriptine on prolactin release from the pituitary gland. Alcohol Clin Exp Res. 2003 Jun;27(6): 975-80.

75 Guivarc'h D, Vernier P, Vincent JD. Sex steroid hormones change the differential distribution of the isoforms of the D2 dopamine receptor messenger RNA in the rat brain. Neuroscience. 1995 Nov;69(1):15966.

76 Guivarc'h D, Vincent JD, Vernier P. Alternative splicing of the $\mathrm{D} 2$ dopamine receptor messenger ribonucleic acid is modulated by activated sex steroid receptors in the MMQ prolactin cell line. Endocrinology. 1998 Oct; 139(10):4213-21.

77 Cristina C, Díaz-Torga GS, Goya RG, Kakar SS, Perez-Millán MI, Passos VQ, et al. PTTG expression in different experimental and human prolactinomas in relation to dopaminergic control of lactotropes. Mol Cancer. 2007 Jan 12;6:4.

78 Delgrange E, Vasiljevic A, Wierinckx A, François $P$, Jouanneau E, Raverot G, et al. Expression of estrogen receptor alpha is associated with prolactin pituitary tumor prognosis and supports the sex-related difference in tumor growth. Eur J Endocrinol. 2015 Jun;172(6): 791-801.
79 Klinge CM. miRNAs and estrogen action. Trends Endocrinol Metab. 2012 May;23(5): 223-33.

80 Vrtacnik P, Ostanek B, Mencej-Bedrac S, Marc J. The many faces of estrogen signaling. Biochem Med. 2014;24(3):329-42.

81 Yu RM, Chaturvedi G, Tong SK, Nusrin S, Giesy JP, Wu RS, et al. Evidence for microRNA-mediated regulation of steroidogenesis by hypoxia. Environ Sci Technol. 2015 Jan 20, 49(2):1138-47.

82 Yao G, Yin M, Lian J, Tian H, Liu L, Li X, et al. MicroRNA-224 is involved in transforming growth factor-beta-mediated mouse granulosa cell proliferation and granulosa cell function by targeting Smad4. Mol Endocrinol. 2010 Mar;24(3):540-51

83 Liang M, Yao G, Yin M, Lü M, Tian H, Liu L, et al. Transcriptional cooperation between p53 and NF- $\kappa$ B p65 regulates microRNA-224 transcription in mouse ovarian granulosa cells. Mol Cell Endocrinol. 2013 May 6; 370(1-2):119-29.

84 Hossain A, Kuo MT, Saunders GF. Mir-17-5p regulates breast cancer cell proliferation by inhibiting translation of AIB1 mRNA. Mol Cell Biol. 2006 Nov;26(21):8191-201.

85 Mansoori B, Mohammadi A, Gjerstorff MF, Shirjang S, Asadzadeh Z, Khaze V, et al. miR$142-3 p$ is a tumor suppressor that inhibits estrogen receptor expression in ER-positive breast cancer. J Cell Physiol. 2019 Feb 11. Epub ahead of print.

86 Spizzo R, Nicoloso MS, Lupini L, Lu Y, Fogarty J, Rossi S, et al. miR-145 participates with TP53 in a death-promoting regulatory loop and targets estrogen receptor-alpha in human breast cancer cells. Cell Death Differ. 2010 Feb;17(2):246-54. 